\title{
CONTRIBUIÇÕES DA EDUCAÇÃO SOMÁTICA PARA OS PROFISSIONAIS DA ÁREA DA SAÚDE HOSPITALAR
}

\author{
THE CONTRIBUTIONS OF \\ SOMATIC EDUCATION FOR \\ THE PROFESSIONALS OF \\ HEALTHCARE SERVICES
}

Edlene Maldonado Gama*

Evanize Romarco Siviero** Sirlane Maria do Carmo Silva $a^{* * *}$

Marciley Ribeiro Barbosa***

\section{RESUMO}

O projeto extensionista "Práticas somáticas aplicadas aos funcionários e servidores do Hospital São João Batista - Fundação Assistencial Viçosense", vinculado ao programa PIBEX, teve como objetivo principal pesquisar e analisar as contribuições das práticas somáticas no tratamento e prevenção das disfunções psicossomáticas dos funcionários e servidores deste hospital, que se localiza no município de Viçosa-MG. Participaram deste estudo 115 funcionários, divididos em diversos setores do hospital. Para a coleta de dados, foram utilizados questionário diagnóstico inicial, diário de bordo e entrevista focal. Por meio das anotações no diário de bordo e resultados das entrevistas focais, percebemos que as sessões práticas proporcionaram aos participantes bem-estar físico e mental, bem como contribuíram para amenizar ou sanar tensões e estresses relacionados a jornadas ininterruptas de trabalho. Concluímos que as práticas somáticas podem trazer bem-estar integral aos indivíduos, no sentido de que equilibram as funções corpo e mente.

Palavras chave: Educação somática. Disfunções psicossomáticas. Lian Gong.

\section{ABSTRACT}

The outreach project "Somatic Practices Applied to the Employees of São João Batista Hospital - Assistance Foundation of Viçosa", which is linked to PIBEX program, aimed to research and analyse the contributions of somatic practices in the treatment and prevention of psychosomatic disorders of employees of São João Batista Hospital, located in Viçosa-MG. Participants were on average 115 employees divided into several sectors of the hospital. For data collection, it was used questionnaire initial diagnosis, logbook and focal

* Aluna de Graduação da Universidade Federal de Viçosa (UFV), MG - Brasil. E-mail: didi.maldonado79@gmail.com

** Professora da Universidade Federal de Viçosa (UFV), MG - Brasil. E-mail: eva.siviero@gmail.com

*** Aluna de Graduação da Universidade Federal de Viçosa (UFV), MG - Brasil. E-mail: sirlaneapov@gmail.com

**** Aluno de Graduação da Universidade Federal de Viçosa (UFV), MG - Brasil. E-mail: marcileyribeiro@yahoo.com.br 
interview. Through the notes in the logbook and results of focal interview, it was realized that the practice sessions gave the participants physical and mental well being as well as contributed to ameliorate or mitigate tensions and stresses related to the uninterrupted working hours. It was concluded that somatic practices can bring well-being to people at the moment that it balances the functions body and mind.

Keywords: Somatic Education. Psychosomatic disorders; Lian Gong.

\section{Introdução}

Por meio dos estudos desenvolvidos no Grupo de Estudos de Dança e Educação Somática (GEDES), surgiu o interesse das autoras deste artigo em realizar um trabalho extensionista junto aos profissionais do Hospital São João Batista de Viçosa - Minas Gerais, com o intuito de proporcionar melhores condiçóes de trabalho aos seus funcionários, conscientizando-os de suas posturas, com um olhar mais sensível e apurado para os processos psicossomáticos que podem se desenvolver devido a condiçóes estressantes no ambiente de trabalho. Segundo Teles (1999), os processos psicossomáticos ou distúrbios psicofisiológicos, como úlceras, certas formas de pressão alta, enxaquecas, asma, dores estomacais, eczemas, alergias de pele de um modo geral, entre outros sintomas, podem surgir quando os indivíduos são submetidos a situaçóes de tensão prolongada (estresse).

É certo afirmar que, na área da saúde, há grande desgaste físico e psicológico dos trabalhadores devido ao cumprimento de muitas horas de jornadas ininterruptas; à organização complexa do atendimento aos pacientes; à estrutura e às normas da instituição, que muitas vezes devem ser atendidas, o que gera uma desvalorização das condiçóes de trabalho essenciais para a saúde do trabalhador. Nestas condições, alguns sintomas elevam o sentimento de desgaste emocional e a incidência de doenças psicossomáticas aumentam, como cefaleias, distúrbios do sono, cansaço mental e dores musculares.

O GEDES foi formado em 2007 por professores e alunos do Curso de Dança da Universidade Federal de Viçosa (UFV), do Departamento de Artes e Humanidades (DAH). Este grupo faz parte do Grupo de Pesquisa Transdisciplinar em Dança da UFV e tem o intuito de pesquisar, por meio das teorias e das práticas somáticas, as funçóes preventivas, terapêuticas e educacionais dessas atividades corporais. Além disso, os membros do grupo buscam vivenciá-las, aplicando diversas técnicas somáticas que visam à saúde psicoemocional, corporal e social dos praticantes, com o intuito de melhorar a sua qualidade de vida e de trabalho. O Grupo, desde sua formação, vem atuando em diálogo com a perspectiva da UFV, trabalhando de forma indissociável às dimensôes do ensino, pesquisa e extensão.

Por esta razão, o GEDES - por meio de um programa de práticas corporais somáticas - teve como objetivos analisar as contribuiçóes das práticas de educação somática, especificamente o Lian Gong em 18 terapias, no tratamento e prevenção das disfunçóes psicossomáticas dos funcionários do Hospital São João Batista, e auxiliá-los no processo de integração no ambiente de trabalho.

\section{As práticas somáticas}

Para discorrer sobre o assunto, recorremos aos autores Bolsanello (2010), Lima (2010), Moreira (1997) e Siviero (2004). Para esses autores, as práticas somáticas ou terapias somáticas visam o desenvolvimento da consciência corporal, bem como a relação do corpo com o ambiente. Dentro dessa perspectiva, o corpo é visto como um corpo-vivo, subjetivo, único; e, através desse corpo-próprio, o indivíduo apreende o meio circundante e investiga conscientemente sua própria interioridade, na busca pelo autoconhecimento. Os 
praticantes de educação somática irão estabelecendo uma nova relação com o mundo, que vai sendo construída através das experimentaçóes e sensaçôes do corpo com o meio, num processo de reapropriação do sentir o corpo no espaço.

Até a época moderna, o intelecto e a racionalidade sempre foram muito valorizados, em detrimento da sensibilidade e sensaçóes que o corpo captava do meio. Acreditavase que a consciência era atributo apenas desta racionalidade, da intelectualidade, e que através dela o homem alcançaria a verdade e seria capaz de entender e explicar o mundo (MOREIRA, 1997). No entanto, na contemporaneidade, a dualidade corpo e mente vem sendo questionada principalmente pela Fenomenologia, que define a consciência como percepção da sensibilidade e da racionalidade. Nesse novo olhar sobre o indivíduo, encontramos a visão da indivisibilidade do indivíduo ou a unidade corpo-mente.

A educação somática, em consonância com a Fenomenologia, vem justamente propor um olhar diferente sobre o indivíduo e suas relaçóes com o mundo. Ela se utiliza de variadas técnicas, como: Bartenieff, Antiginástica, Técnica Alexander, Ideokinesis, Feldenkrais, Eutonia, Ginástica Holística, Cadeias musculares e articulares G.D.S., Body-Mind Centering, Ginástica Sensorial, Continuum, Somaritmos, Pilates, Gyrotonic, técnicas orientais que foram trazidas para o ocidente, etc. Todas elas procuram entender, investigar e perceber o corpo de uma maneira revolucionária, avessa ao tratamento que a sociedade dá a esse corpo que embrutece, normatiza e formaliza. A educação somática procura descobrir a história de vida de cada um, num processo de escuta corporal; ela quer saber sobre as experiências de vida, que são únicas e pessoais (BOLSANELLO, 2010).

Na perspectiva do Reagrupamento pela Educação Somática (RES):

A educação somática propóe uma descoberta pessoal de seus próprios movimentos, de suas próprias sensaçóes. Este processo educativo é oferecido em cursos ou liçóes onde o orientador propóe pela palavra, ou ainda pelo gesto ou tocar, atividades pedagógicas de movimento e percepção do corpo. (R.E.S., 2009 apud LIMA, 2010, p. 64) ${ }^{1}$

\section{O projeto extensionista com as práticas somáticas}

Nos anos de 2014 e 2015, com o apoio do Programa Institucional de Bolsas de Extensão Universitária (PIBEX) da UFV, as autoras e colaboradores do projeto intitulado "Práticas somáticas aplicadas aos funcionários e servidores do Hospital São João Batista - Fundação Assistencial Viçosense (FAV)" realizaram um trabalho com as práticas somáticas junto aos profissionais da área de saúde, no município de Viçosa MG. Dentre as diversas técnicas somáticas já mencionadas, empregamos com estes funcionários exercícios de relaxamento, utilizando a respiraçáo como facilitadora; técnicas de massagem e automassagem; consciência do corpo e de suas partes, através de exercícios de centramento; percepção do corpo no espaço e percepçáo do movimento.

1 R.E.S. (Le Regroupement pour l'éducation somatique), Reagrupamento pela educação somática: organismo sem fins lucrativos, fundado em 1995, em Quebec, Canadá. Lugar de troca, de pesquisa e de ações pelo avanço e pela prática da educação somática. Reconhece como métodos de educação somática: a Técnica de Alexander, o Método de Feldenkrais, a Aproximação Global do Corpo e Método de Liberação das Couraças e a Ginástica Holística da Dra. Ehrenfried. 
Figura 1 - Massagem com bolinhas nos pés. Setor: Lavanderia

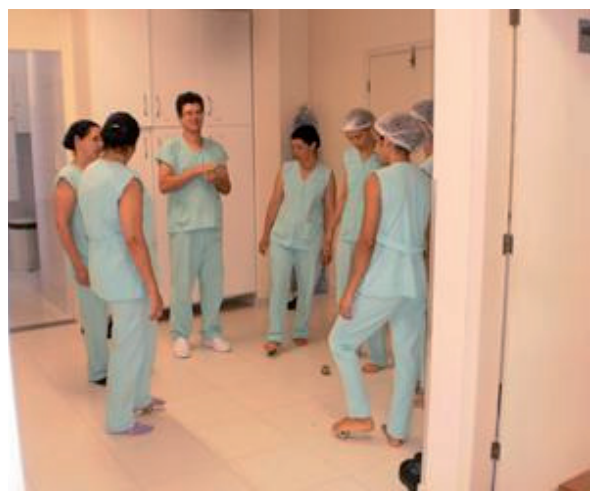

Fonte: GEDES (2014)

\section{A Técnica do Lian Gong}

Nossa equipe de trabalho com as práticas somáticas junto aos funcionários participantes deste estudo teve como foco principal a técnica do Lian Gong (lê-se Lian Kun), em 18 Terapias Anterior (Lian Shi Ba Fa) - 1a parte, que previne e trata de dores no pescoço, nos ombros, nas costas, na regiáo lombar, nos glúteos e nas pernas.

Esta técnica foi desenvolvida pelo médico ortopedista chinês Dr. Zuang Yuen Ming, baseada em princípios da Medicina Tradicional Chinesa. Consiste em movimentaçôes lentas, com alongamento e tração corporal dentro dos limites do corpo do praticante, utilizando a respiraçá̃o para dar ritmo ao movimento, agindo de forma suave sobre o organismo (MING, 2000; CARON; RODRIGUES, 2011; SANTOS, 2011; SIVIERO, 2004).

No Brasil, a ginástica foi introduzida em 1987, pela professora Maria Lúcia Lee, a qual fundou uma Associação Brasileira de Lian Gong, no momento sediada em Belo Horizonte, MG. Esta Associaçáo tem o objetivo de difundir e aperfeiçoar o ensino do Lian Gong, como também outras técnicas orientais, colocando em prática a ideia de melhoria da qualidade de vida da população brasileira (SIVIERO, 2004). Dentre os benefícios desta técnica, citamos: redução da ansiedade, por meio da diminuição dos desequilíbrios causados pelas emoções negativas; redução dos sintomas de estresse, melhora das funçôes cognitivas; aumento da eficácia da função cardiovascular; melhora nos hábitos do sono (SIVIERO, 2004; MING, 2011; SANTOS; RODRIGUES; CARON, 2011).

Buscando uma melhor qualidade de vida e saúde, a técnica do Lian Gong procura harmonizar os praticantes com o meio, estimulando também os indivíduos a terem participação ativa e autonomia sobre seu próprio bem-estar, num processo de busca pelo autoconhecimento e participaçáo em sociedade de vida plena, em harmonia com a natureza (MING, 2011; SANTOS; RODRIGUES; CARON; 2011).

Para exemplificar um pouco dessa técnica oriental, vejamos a seguir as ilustraçóes e descriçóes ${ }^{2}$ que demonstram alguns exercícios da primeira parte - primeira série do Lian Gong.

Lian Gong $1^{\text {a }}$ série - Exercícios que previnem e tratam de dores na regiáo do pescoço e ombros (cervicalgia, torcicolo, tensão acumulada, periartrite na articulação dos ombros).

2 Descrição retirada do livro Lian Gong Shi Ba Fa (Lian Gong em 18 Terapias), pelo Dr. Zhuang Yuan Ming, criador da Ginástica. (MING, 2011) 
Figura 2 -llustração do Exercício 1 - Movimento do pescoço

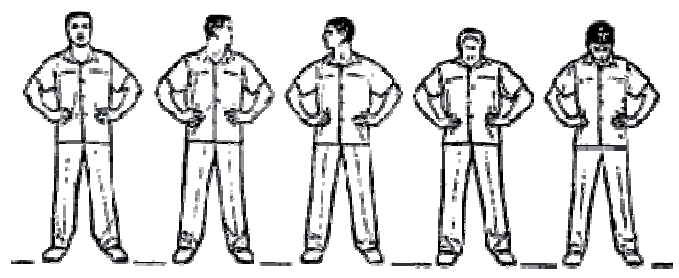

Fonte: Villasboas (2016)

Movimento do pescoço: pés separados na largura dos ombros, máos na cintura. Movimentos: girar a cabeça lentamente para a esquerda e para a direita, até o seu limite. Voltar a cabeça para frente. Levantar lentamente a cabeça, olhar para cima. Voltar à posição inicial. Abaixar lentamente a cabeça, olhar para baixo. Voltar à posição inicial.

Figura 3 - Exercício 2 - Arquear as mãos

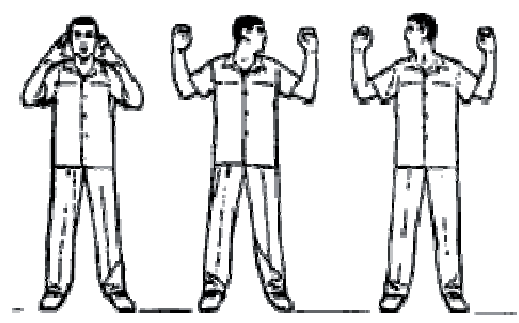

Fonte: Villasboas (2016)

Arquear as máos: os pés separados na largura dos ombros, mãos com as palmas estendidas na frente do rosto, formando um triângulo. Movimento: as máos afastam lentamente uma da outra, fechando os punhos até estarem ao lado do tronco. Ao mesmo tempo, a cabeça gira para o lado esquerdo. O olhar acompanha a máo e os antebraços ficam perpendiculares ao chão. Voltar para posição inicial. Repetir o movimento, mas girar a cabeça para o lado direito.

Figura 4 - Ilustração do Exercício 3 - Estender as palmas para cima.

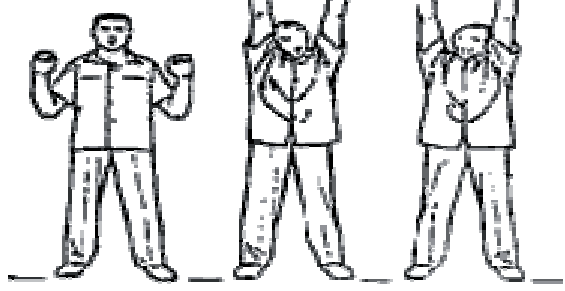

Fonte: Villasboas (2016)

Estender as Palmas para cima: pés separados na largura dos ombros, braços flexionados de maneira natural ao lado do corpo, punhos fechados na altura dos ombros. Movimento: as máos se abrem lentamente, à medida que os braços se elevam, os olhos acompanham a mão esquerda até o alto. Voltar à posição inicial, abaixando os braços e 
acompanhando a máo esquerda com o olhar. Repetir o movimento da figura um e dois e três, mas com o olhar acompanhando a mão direita.

Figura 5 - Ilustração do Exercício 4 - Expandir o peito.

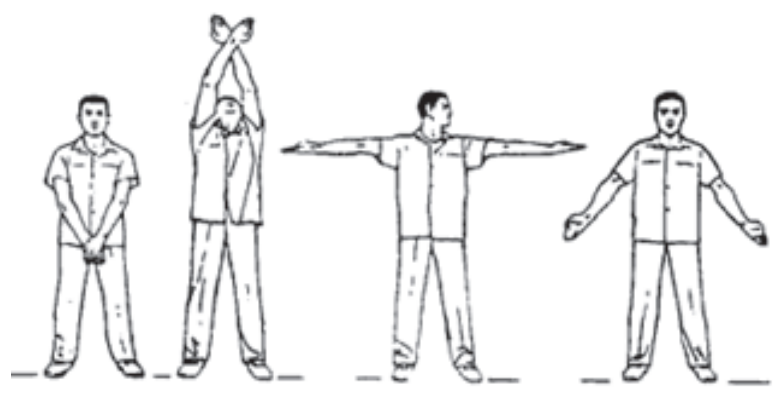

Fonte: Villasboas (2016)

Expandir o Peito: pés separados na largura dos ombros, mãos sobrepostas na frente do corpo. Movimento: o olhar acompanha a elevação das mãos sobrepostas. Girar as mãos até as palmas se voltarem para cima, traçando uma curva pela lateral do corpo, por trás da linha dos ombros. O olhar acompanha a mão (Fig.3). Voltar à posiçáo inicial, mas com a mão direita sobre a esquerda e repetir novamente o movimento, mas com o olhar acompanhando a mão direita.

Figura 6 - Ilustração do Exercício 5 - Despregar as asas.

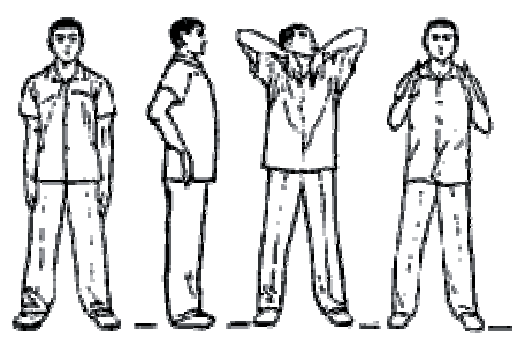

Fonte: Villasboas (2016)

Despregar as asas: pés separados na largura dos ombros (Fig.1). Flexionar os braços até levá-los a partir do cotovelo, fazendo uma curva por trás da linha lateral do corpo. A cabeça vira para a esquerda, acompanhando com o olhar o movimento do cotovelo, até olhar para frente, no momento que os cotovelos estejam para cima e as mãos para baixo. As mãos ficam estendidas na frente do rosto (Fig. 4). Os braços descem lentamente pela frente do corpo e voltam à posição inicial.

Figura 7 - Ilustração do Exercício 6 - Levantar os braços de ferro.

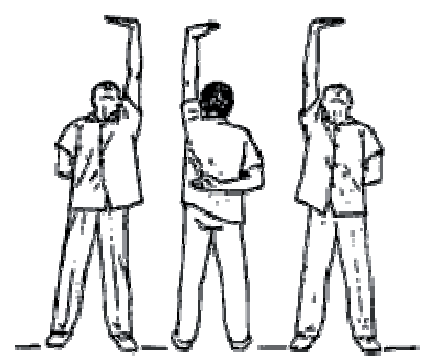

Fonte: Villasboas (2016) 
Levantar os braços de ferro: pés separados na largura dos ombros. Movimento: o olhar acompanha o movimento da mão esquerda, que se eleva pela linha lateral do corpo com o braço estendido, olhar para cima quando a mão chegar ao limite do movimento. Ao mesmo tempo, a máo direita se posiciona atrás do corpo, com o braço flexionado e o dorso da mão encostando-se à região lombar. $\mathrm{O}$ olhar acompanha a mão esquerda, que desce pela lateral do corpo até se posicionar acima da mão direita. Repetir o movimento pelo lado direito.

É importante observar alguns itens na prática desta técnica chinesa. Como por exemplo, praticar com entusiasmo e otimismo. O estado de ânimo é importantíssimo para que os exercícios atuem de forma benéfica no organismo, e possam trazer resultados positivos para a saúde e o bem-estar dos praticantes do Lian Gong. Executar os movimentos corretamente é outro ponto que vale ressaltar junto aos praticantes. Devemos observar as posturas corretas das mãos, dos pés e o alinhamento correto do corpo durante a prática dos exercícios. Buscar a percepçáo sensorial do QI, ou seja, sentir a presença de bem-estar, calor, intumescimento ácido (dor ácida) durante a execução dos exercícios. Desta maneira, poderemos ter sucesso na prática, obtendo um resultado terapêutico positivo. Persistência e regularidade no treinamento dos exercícios também é outro ponto que devemos frisar junto aos praticantes desta técnica, pois estabelecer ordem e disciplina na vida cotidiana melhora a capacidade funcional do corpo, elevando também o seu metabolismo. Outra questáo levantada pelos criadores do método é respeitar os limites do corpo e aperfeiçoar gradativamente os exercícios. Não forçar o corpo, saber a dosagem da prática; este limite é bem particular, é de cada um. Devemos respeitar o condicionamento físico de cada praticante. Por fim, devemos buscar coordenar o movimento com a respiraçáo, buscando sempre um ritmo, pois uma movimentaçáo sem ritmo leva ao cansaço. Vale a pena ressaltar que o praticante nunca deve prender a respiração. No início, pode ser um pouco complexo aos praticantes coordenarem as açóes de movimento e respiração simultaneamente, portanto, quando se começa a praticar o Lian gong, deve-se deixar a respiração mais livre, até que os praticantes se familiarizem com os movimentos (MING, 2011).

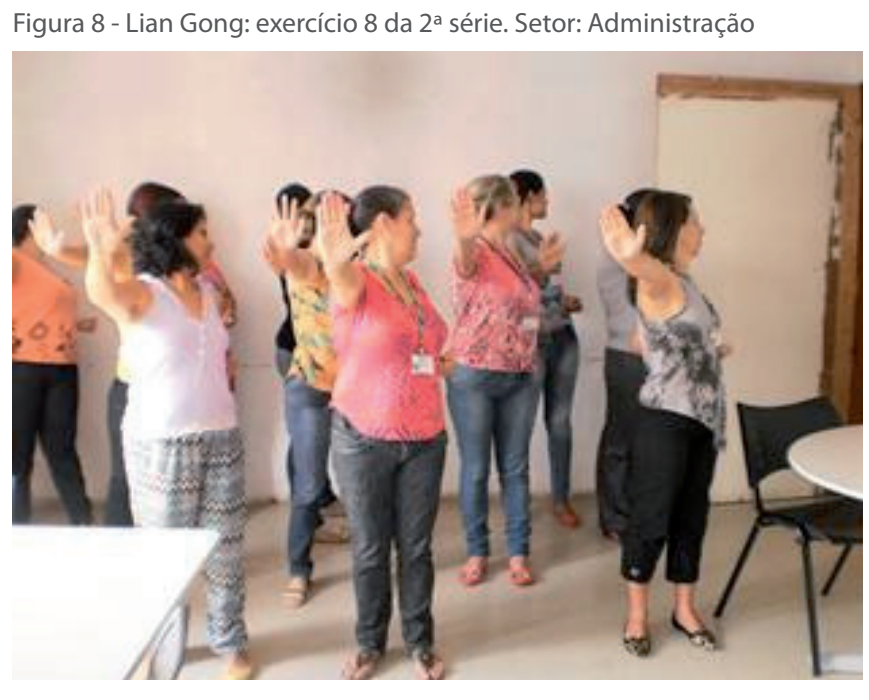

Fonte: GEDES (2014) 


\section{Método}

Para analisar e verificar as contribuiçôes da educação somática no tratamento e prevenção das disfunçóes psicossomáticas dos participantes deste projeto, foi feito um estudo de caráter exploratório descritivo-explicativo de natureza qualitativa. Também foi realizada uma revisão de literatura com as palavras-chave: educação somática, síndromes doloridas, disfunções psicossomáticas e Lian Gong, em bases de dados científicas on line, bibliotecas digitais e bibliotecas da UFV.

O público-alvo foram 115 funcionários do Hospital Sáo João Batista, divididos entre os diversos setores do hospital, como: Enfermarias (Alas C: 6 participantes, Ala D: 4 participantes; Ala E: 5 participantes; Ala F: 3 participantes; Ala G: 7 participantes); Lavanderia: 14 participantes; Higienização: 21 participantes; CME (Centro de Esterilizaçáo de Materiais): 8 participantes; Farmácia: 4 participantes; Almoxarifado: 2 participantes; Hemodiálise: 5 participantes; Hemodinâmica: 6 participantes; Telefonia: 2 participantes; Copa/Cozinha: 13 participantes; Administração: 13 participantes, e Recepçáo: 2 participantes

As sessões de práticas somáticas foram realizadas por 3 membros do GEDES, todos graduandos do Curso de Dança da UFV e organizadores do projeto, entre os anos de 2014 e 2015. No período de fevereiro a dezembro de 2014, as práticas corporais somáticas no ambiente hospitalar foram feitas separadamente em cada setor, de 2 a 3 vezes por semana, com pausas de 20 minutos, durante o horário de expediente destes profissionais da saúde, no período diurno do hospital. Os setores atendidos neste ano foram: enfermarias: Ala C, Ala D, Ala E, Ala F e Ala G; Lavanderia; Administração; Recepção; Copa/Cozinha e Hemodinâmica.

No ano de 2015, cada setor realizou a prática de 1 a 2 vezes na semana, portanto, houve uma reduçáo do número de práticas realizadas por semana, porém conseguimos ampliar o atendimento aos turnos de trabalho do hospital. Além do período diurno, atendemos também os funcionários no período noturno. Os setores atendidos no ano de 2015 foram: Lavanderia; Higienização; CME; Farmácia; Almoxarifado; Hemodiálise; Hemodinâmica; Telefonia; Copa/Cozinha e Administração.

Como critério de inclusão dos funcionários destes setores, estes tiveram uma frequência maior e igual a $60 \%$ nas aulas.

A equipe do Projeto utilizou três instrumentos para a coleta dos dados: o questionário diagnóstico inicial, o diário de bordo e as entrevistas focais. Nas aulas de massagem, os materiais utilizados foram bolinhas (bolas de borracha macias com cravo e lisa e bolas de tênis), com o objetivo de aliviar dores e tensóes nas costas (regiốes dos ombros, regiốes da coluna cervical, torácica e lombar). Também foram empregadas para redução de cansaço e desconforto nos pés e pernas; além disso, nas regiôes dos pés encontramos pontos reflexos que beneficiam também órgáos internos do corpo. Essas massagens foram realizadas de diversas maneiras pelos participantes, como: automassagem, massagens em duplas, em grupo ou utilizando uma parede como forma de apoio para massagear o corpo. Experimentamos realizá-las em diferentes posiçóes corporais, como em pé e assentadas, com o tronco ereto, com o tronco relaxado etc.

É importante ressaltar que, para o desenvolvimento deste trabalho, mesmo sendo este de extensão, ele foi submetido ao Comitê de Ética da UFV (CAAE no 45254515.4.0000.5153.), porque acreditamos que pesquisa e extensão neste estudo 
estavam indissociadas. Desta forma, o participante sempre foi lembrado que seu nome náo seria mencionado no estudo, sendo substituído por um código, para preservar a sua identidade. Caso algum participante náo soubesse escrever, a pesquisadora leria o questionário diagnóstico, preenchendo-o de acordo com a resposta que lhe fosse fornecida.

Quanto às sessóes com as práticas corporais, por serem exercícios lentos e suaves, trabalham a respiração de maneira mais tranquila e não causam danos fisiológicos ou desconforto aos praticantes. Na maioria das vezes, as sessóes foram realizadas em pé, buscando alongar e relaxar regióes específicas do corpo, através da percepçáo dos estados emocionais e das tensóes e dores musculares.

\section{Investigando as condiçóes psicofísicas dos participantes Da condiçáo inicial: Questionário diagnóstico inicial}

O primeiro instrumento utilizado pela equipe do Projeto foi o questionário diagnóstico inicial, por meio do qual tínhamos como objetivo investigar as condiçóes físicas e psicológicas dos participantes, bem como saber sobre a rotina de trabalho destes profissionais da saúde.

Neste questionário diagnóstico inicial, procuramos investigar se os profissionais trabalhavam carregando peso; quantas horas trabalhavam em pé ou assentado. Além disso, buscamos saber se eles apresentavam algum problema de saúde; se sentiam dores e/ ou tensóes pelo corpo e quais seriam essas áreas do corpo. É interessante ressaltar que o questionário foi aplicado individualmente, separadamente, em cada setor do hospital; e que o instrumento foi utilizado como ponto de partida para a elaboraçáo dos programas de educaçáo somática, desenvolvidos junto aos participantes do estudo.

Através da compilação dos dados deste instrumento nos anos de 2014 e 2015, percebemos as maiores demandas dos funcionários e servidores participantes do Projeto.

\section{Da condiçáo de amenizaçáo dos sintomas psicossomáticos - Entrevistas focais I e II}

Outro instrumento utilizado para saber das condiçôes psicofísicas dos participantes foram duas entrevistas focais. A primeira foi realizada no meio do ano e a segunda no final do ano. Tais entrevistas foram aplicadas em grupo, separadamente, em cada setor do hospital, antes da sessáo somática. Os membros da equipe do projeto que aplicaram as sessões práticas levaram um gravador e realizaram uma conversa informal, buscando deixar os participantes à vontade; porém, tínhamos um roteiro com perguntas que foi seguido durante essa fase do projeto. Este instrumento, além de investigar mudanças nas condiçóes físicas e psicológicas dos participantes após realizarem as sessóes com as práticas somáticas, procurava saber quais atividades aplicadas nas sessóes eles gostavam mais de realizar, e se as atividades lhes trouxeram algum benefício com relação à saúde psicoemocional. 


\section{Das percepçóes e falas dos participantes: Diário de Bordo}

No diário de bordo, dos membros da equipe do Projeto foram anotadas todas as percepçóes sobre as aulas práticas, bem como foram anotadas as falas dos participantes do estudo. Por meio de conversas informais, antes de iniciarmos as sessóes somáticas, notamos que muitos dos profissionais da saúde se sentem sobrecarregados e estressados em sua rotina de trabalho, devido às jornadas ininterruptas e/ou excesso de zelo que necessitam ter para o bom andamento das atividades e atendimento aos pacientes do hospital. Este instrumento também orientou toda a equipe na reformulação do programa com as práticas somáticas, no momento em que buscamos atender à demanda dos participantes em cada setor do hospital.

\section{Resultados e discussóes}

Primeiramente, antes de adentrarmos nos resultados deste estudo, vamos traçar um perfil dos funcionários participantes. Observamos que a rotina de trabalho influenciou bastante nos locais onde apareceram dores e tensóes pelo corpo. A idade dos participantes variou entre 30 e 55 anos e cerca de $70 \%$ eram mulheres. A maioria dos funcionários trabalhava todo o tempo assentados, digitando ou com movimentos repetitivos.

Por meio da compilação dos dados do questionário diagnóstico inicial, verificamos as áreas do corpo em que os funcionários apresentavam tensóes e as áreas em que se queixavam de dores.

No Gráfico 1 verificam-se os principais problemas relatados: dores na regiáo dos ombros, lombar e regiáo torácica.

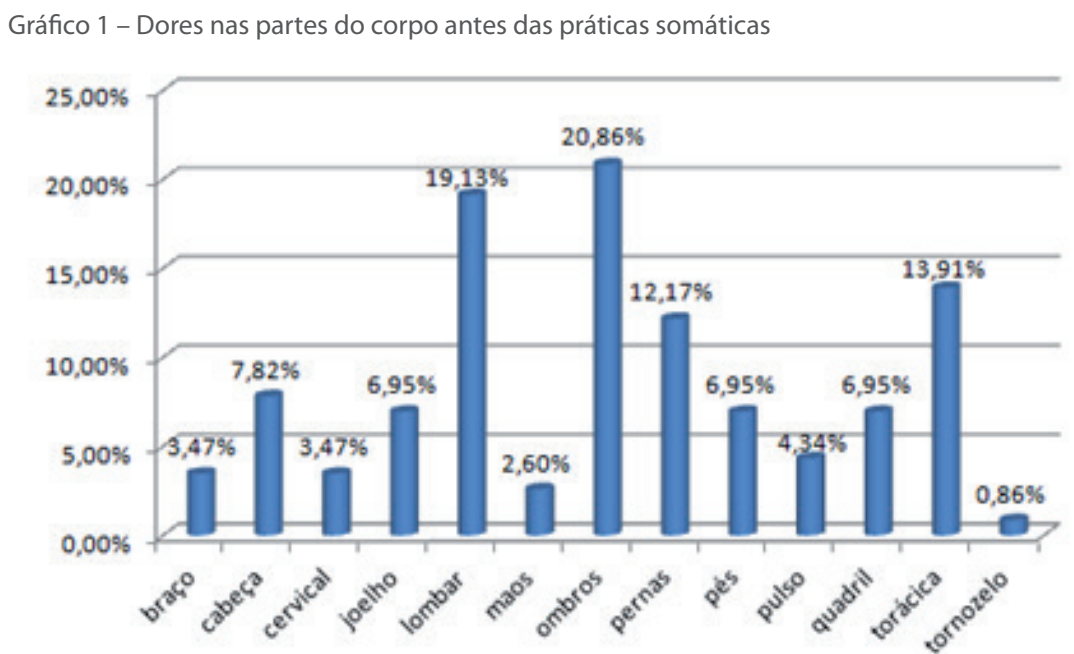

Fonte: GEDES (2014)

As áreas do corpo mais tensas relatadas foram os ombros, regióes da coluna torácica, lombar e cervical, como aponta o Gráfico 2. 
Gráfico 2 - Tensões no Corpo antes das práticas somáticas

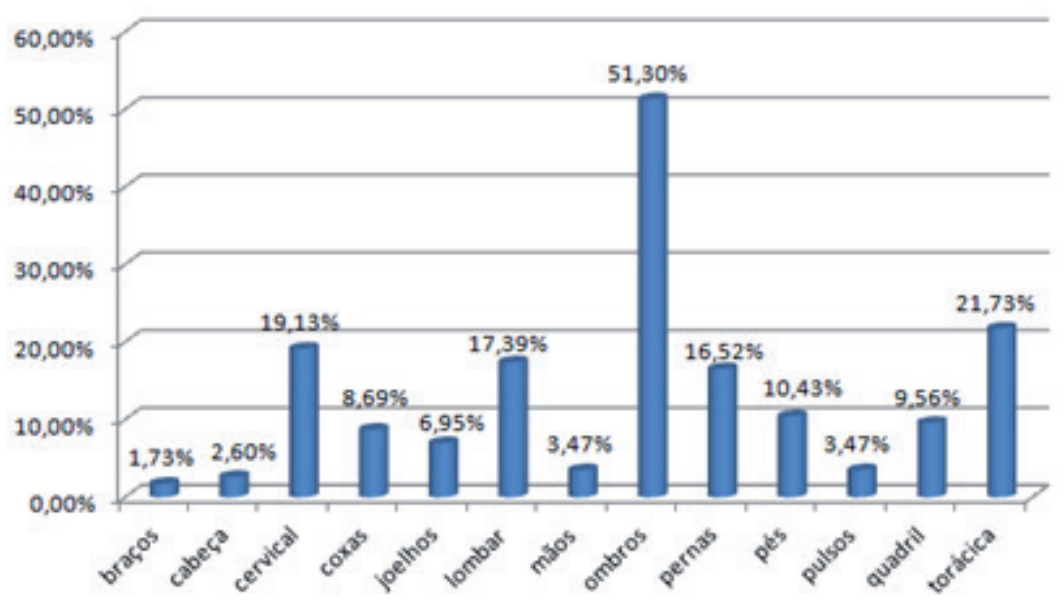

Fonte: GEDES (2014)

Após diversas sessóes com as práticas somáticas, quando desenvolvemos junto aos funcionários exercícios de alongamento do Lian Gong, exercícios de respiraçáo e massagens com as bolinhas terapêuticas, notamos significativas mudanças no estado físico dos participantes. Eles nos relataram que, após a execução das sessóes, sentiram uma melhora imediata de dores e/ou tensóes em diversas partes do corpo, como: ombros, coluna vertebral, principalmente nas regióes torácica e lombar, dores nos braços; dores e queimação nas solas dos pés, dentre outros sintomas mencionados:

"Sentia uma queimação nas solas dos pés e comecei a fazer a massagem com a bolinha em casa. Agora não sinto mais essa queimação." (Participante 17);

"Estava sentindo uma dor intensa no ombro, fiz um alongamento de braços que você deu e melhorou bastante. Gosto muito de todas as atividades, mas esse dia foi bastante especial." (Participante 8);

Nesse dia estava sentindo muita dor pelo corpo e saí muito bem depois da aula, a dor foi embora. Esses exercícios que fazemos nas sessóes práticas tiram toda a dor do corpo. Gosto de todos os exercícios." (Participante 10)

Notamos também melhora na condição respiratória de alguns funcionários. A prática constante das atividades de educaçáo somática leva os indivíduos a uma harmonizaçáo dos sistemas físicos e energéticos que integram todo o ser e, desta maneira, conseguimos (re)estabelecer equilíbrio e harmonia ao organismo:

"Antes, no final do plantão eu me sentia cansada, com dificuldade pra respirar, tinha que dar uma parada no meio do morro quando ia pra casa. E agora to bem melhor e com as aulas melhorou bastante." (Participante 81)

Segundo Ming (2010) e Siviero (2004), os movimentos do Lian Gong devem estar coordenados ao ritmo natural da respiração, que deve ser inspirar pelo nariz e expirar pela boca. Os movimentos devem ser amplos, contínuos e equilibrados para aumentar a capacidade pulmonar, tornando a respiração mais longa e profunda. Desta forma, o diafragma também está sendo exercitado, beneficiando o aparelho respiratório, o coração e o sistema circulatório, o que faz com que o participante se sinta melhor e menos cansado.

Através dos instrumentos utilizados neste estudo, percebemos que as práticas somáticas, mais especificamente o trabalho com o Lian Gong, que foi o mais abordado 
pelo Projeto, ajudou bastante os funcionários do hospital a conhecerem e perceberem seus corpos numa dimensão fisiológica e cinesiológica. Desta maneira, um olhar mais detalhado para a postura e para certas regióes do corpo, assim como para as sensaçóes, identificando, por exemplo, uma postura inadequada, pode ajudá-los a prevenir uma série de disfunçóes ocasionadas pelo excesso de trabalho ininterrupto ou por problemas psicológicos, causadas pelo período laboral.

Exemplos disso estão presentes nas falas dos participantes:

"Eu tinha muitas dores na regiáo lombar por ficar muito tempo sentada e os exercícios me aliviaram, principalmente os do Lian Gong." (Participante 2)

"Gostei da massagem nos pés, das informaçôes que você trouxe, mostrando as áreas do pé, relativas aos órgãos internos do corpo. Depois da massagem nos pés senti que relaxei bastante a região lombar, regiấo do pescoço e região torácica." (Participante 45)

As sessōes práticas conseguiram também melhorar o estado de ânimo dos funcionários, reduzindo o cansaço físico e mental, agindo no seu estado motivacional para retornarem ao trabalho. A maioria relatou que, após os exercícios nas sessóes somáticas, sentiram-se revigorados, com mais ânimo para realizarem suas atividades laborais:

"Depois dos exercícios fico mais relaxado, mais leve; me sinto com mais energia para trabalhar." (Participante 33)

Segundo Siviero (2004 p. 178), "Precisamos sair dos padróes habituais e reeducar nosso corpo, tornando-o mais sábio [...]", e as práticas corporais somáticas proporcionam esse caminho, pois as técnicas fazem com que o corpo deixe de ser um receptor passivo e torna-se ativo.

Após os exercícios, os funcionários também perceberam melhora na concentração, conseguiram desviar a mente de problemas e afazeres pessoais e domésticos, mantendo o foco no trabalho:

"Com relação ao estado emocional a gente fica mais focada, às vezes estamos com um problema, preocupada, depois do exercício ficamos mais focados no trabalho." (Participante 12).

Notamos que o trabalho com as práticas somáticas vem proporcionando bemestar integral, no momento em que procura equilibrar as funçóes do corpo e da mente, proporcionando bem-estar físico e mental. Vem colaborando também para o desenvolvimento de uma melhor qualidade e eficácia no trabalho desempenhado por estes profissionais da saúde, como podemos observar nos relatos das participantes 19 e 10:

"Às vezes a gente fica quebrando a cabeça pra resolver um problema aqui no trabalho, fica agarrado" (Participante 1)

"[...] depois que a gente faz o exercício aqui com você, a gente volta com a mente mais lúcida, parece que tudo fica mais fácil de resolver." (Participante 9)

"O Lian Gong, que estica bem a coluna, foi bom até para o psicológico, porque a gente saiu da rotina e parou um momento para descansar para relaxar, saímos do stress." (Participante 10)

Segundo França e Rodrigues (1997), o estresse pode ser analisado a partir da relação de três fatores, que são os agentes estressores externos (trabalho e relaçôes sociais), o meio 
interno do indivíduo (seus pensamentos e emoçóes), e a circunstância na qual a pessoa está submetida, esta última é avaliada por esse indivíduo como uma ameaça do seu bemestar, exigindo dele mais habilidades ou recurso de que dispóe. É uma relação particular entre o ser, o meio e as circunstâncias que a pessoa está vivenciando.

De acordo com Barstow (1980), o estressor é uma situação ou experiência que gera sentimentos de tensáo, ansiedade, medo ou ameaça, que pode ter origem interna ou externa. O projeto com as práticas somáticas atua justamente com os estressores de origem interna, equilibrando as funçóes do corpo, trazendo bem-estar físico e psicológico e, consequentemente, auxilia os participantes a lidarem melhor com os fatores estressores externos ao trabalho. Enfim, ajuda os profissionais a adequarem-se melhor às circunstâncias de trabalho nas quais estáo atrelados.

Foi relatada pela maioria dos funcionários a presença de sintomas físicos do estresse, como taquicardia, sudorese, tensão muscular, dores de cabeça frequentes, fadiga, insônia, fraqueza física etc. Outros relataram momentos de suas vidas em que sofreram ataques de ansiedade, e hoje, por meio de indicação médica, fazem uso de medicação ansiolítica. Pelos relatos, tais sintomas influenciam negativamente na produtividade destes profissionais, interferindo na qualidade dos serviços prestados. Além disso, os problemas podem ser motivo de ausências e de atestados médicos no trabalho.

Segundo Stacciarini e Tróccoli (2001), as tensóes e os problemas advindos do exercício de uma atividade profissional estão no ranque dos causadores de estresses e, é claro, com uma atenção especial ao trabalho do enfermeiro, por sua própria natureza e características, que revela especialmente suscetível ao fenômeno do estresse ocupacional.

De acordo com estes mesmo autores, há vários fatores que podem tornar o ambiente de trabalho bastante estressante. Condições inadequadas de trabalho, turno de trabalho, carga horária, pagamento, riscos e quantidade de trabalho, grau de responsabilidade para com pessoas e coisas, relaçóes no trabalho (relaçóes difíceis com o chefe, colegas, subordinados, falta de desenvolvimento na carreira, insegurança no trabalho devido a reorganizaçóes, dificuldade no manejamento da interface trabalho-casa).

Devido ao estresse, muitos funcionários relataram, em 2014, consistentes mudanças nas condiçóes de sono, alguns apresentavam dificuldade para dormir ou acordavam várias vezes durante a noite, e com a prática dos exercícios somáticos conseguiram noites de sono mais tranquilas, perceberam o corpo mais relaxado, o que acreditamos ser um resultado expressivo para uma melhora em suas condiçóes de saúde.

\section{Consideraçóes Finais}

De acordo com os resultados, percebemos maiores benefícios das sessões somáticas em 2014, ano em que os funcionários praticaram mais regularmente e com maior frequência do que no ano 2015. Sobre as condiçôes psicofísicas, conseguimos sanar problemas como dificuldades respiratórias, queimação e desconforto nas solas dos pés, tensôes nas regióes dos ombros e melhora nas condiçôes psicológicas desses participantes. Eles relataram que utilizaram os exercícios somáticos ao enfrentarem momentos de estresse no trabalho, bem como empregaram tais técnicas junto aos pacientes atendidos no hospital. 
Já no ano de 2015, as sessōes somáticas foram feitas com menos frequência que no ano anterior, e desta maneira percebemos que as melhoras e os benefícios foram mais momentâneos, ou seja, eles não apresentaram um efeito tão duradouro. Os participantes perceberam que os efeitos das sessóes somáticas permaneceram no corpo apenas no dia em que praticaram os exercícios, e que dores e/ou tensóes no corpo reapareceram no dia seguinte.

Portanto, acreditamos que as práticas somáticas devem ser realizadas sempre que necessário, para que o indivíduo entenda e perceba que as mudanças em seu corpo devem acontecer a todo momento, principalmente quando se sentir em um ambiente estressor; ou se suas atitudes the colocarem em situaçóes que lhe causem tensóes ou dores musculares; ou mesmo quando possam causar disfunçóes psicossomáticas, comprometendo, assim, seu ambiente de trabalho e sua saúde. 


\section{Referências}

BARSTOW, J. Stress variance in hospice nursing. Nurs Outlook, v. 28, n.12, p. 751-4, 1980.

BOLSANELLO, D. P. Em pleno corpo: educação somática, movimento e saúde. Curitiba: Juruá, 2010.

COSTAS, A. M. R. Klauss Vianna e a expressividade como devir dramatúrgico da dança. Disponível em: <http://www.portalabrace.org/vcongresso/textos/pesquisadanca. Acesso em 10 mar. 2014, 8:00.

FRANÇA, A. C. L; RODRIGUES, A. L. Stress e trabalho: guia básico com abordagem psicossomática. São Paulo: Atlas, 1997.

GOUVÊA, P. B.; HADDAD, M. C. L; ROSSANEIS, M. A. Manifestações psicossomáticas associadas à Síndrome de Burnout referidas por trabalhadores de saúde. Revista Saúde, Santa Maria, v. 40, n. 1, p.45-52, jan./jul. 2014.

LIMA, J. A. O. Educação Somática: limites e abrangências. Pro-Posições, Campinas, v. 21, n. 2, p. 51-68, mai./ago. 2010.

MING, Z. Y.; SHEN, Z. J. Lian Gong Hou Shi Ba Fa. São Paulo: Pensamento, 2011. 
MOREIRA, A. R. L. Algumas considerações sobre a consciência na perspectiva fenomenológica de MerleauPonty. Estudos de psicologia, v. 2, n. 2, p. 399-405,1997.

SANTOS, L. M.; RODRIGUES, D. M. O.; CARON, C. V. A utilização da técnica corporal chinesa Lian Gong no estágio supervisionado I e II do Curso de Naturologia Aplicada da Universidade do Sul de Santa Catarina UNISUL. Caderno Acadêmico Tubarão, v. 3, n. 2, p. 50-72, 2011.

SIVIERO, E. K. O papel da ginástica terapêutica chinesa Lian Gong em 18 terapias no comportamento psicomotor e cotidiano de praticantes adultos. 2004. Dissertação (Mestrado) - Universidade Estadual Paulista - UNESP, Rio Claro, SP, 2004.

STACCIARINI, J. M. R.; TRÓCCOLI, B. T. O estresse na atividade ocupacional do enfermeiro. Revista Latinoamericano de Enfermagem, v. 9, n. 2, p. 17-25, mar. 2001.

TELES, M. L. S. O que é stress. Coleção Primeiros Passos. São Paulo: Brasiliense, 1999.

VILLASBOAS, S. L. Taochia. Grupo de Terapia e Artes orientais. Disponível em: <http://www.taochia.pro.br/ liangong1.htm. Acesso em: 10 jan. 2016 